\title{
Short-term Impact of a Web-based COVID-19 Certificate Program on Knowledge of Global Public Health Professionals
}

\author{
Kritika Upadhyay ${ }^{1}$, Sonu Goel ${ }^{2}$
}

\begin{abstract}
Introduction: Despite global strategies for containment adopted so far, the incidence of coronavirus disease-2019 (COVID-19) continues to rise across the globe transcending borders and cultures. The objective of this paper is to evaluate the impact of short-term Web-based COVID-19 certificate program on knowledge of global public health professionals in managing the corona pandemic in their respective countries.

Materials and methods: A series of three webinars were conducted by the Department of Community Medicine and School of Public Health, PGIMER, Chandigarh, between April and May 2020. The program was supported by the Ministry of External Affairs, Government of India, through the Indian Technical and Economic Cooperation Scheme. The program focused on imparting basic knowledge about COVID-19 pandemic and its management to mid- and senior-level healthcare professionals, including program managers, academicians, researchers, and policymakers. The topics covered included 28 lectures under eight modules demonstrating good practices of India ranging from hospital management to field-based surveillance and administrative aspects.

Results: A total of 131 participants from 17 countries of 5 continents (Asia, Africa, North America, South America, Oceania) attended the program. Majority of participants were clinicians $(n=55,42 \%)$ followed by other healthcare staff, viz., lab technicians, pharmacists, information technology managers $(n=42,32.1 \%)$, academicians $(n=19,1.5 \%)$, and public health professionals $(n=15,11.5 \%)$. There was a significant increase in participant's knowledge score $(p<0.0001)$ after the all three programs. Majority $(93.1 \%)$ of participants felt the program was excellent or very good, especially on relevancy of the program (74.4\%) and its application in the workplace $(74.4 \%)$.

Conclusion: The program has not only successfully shown its effectiveness in increasing the knowledge and skills of global participants in managing corona pandemic but also helped in enhancing image of country by showcasing best practices of India to global participants.

Keywords: Capacity building, COVID-19, Cross-sectional study, Knowledge assessment, Management development program, Webinar.

Journal of Postgraduate Medicine, Education and Research (2020): 10.5005/jp-journals-10028-1406
\end{abstract}

\section{INTRODUCTION}

Despite global strategies for containment adopted so far, the incidence of coronavirus disease-2019 (COVID-19) continues to rise across the globe transcending borders and cultures. ${ }^{1}$ As of June 18 , 2020, the World Health Organization (WHO) had reported 8.24 million confirmed cases and 446,000 confirmed deaths. ${ }^{2}$ Almost every country or territories are affected by this pandemic of twenty-first century. Total 82 nations (almost a third of global population) have announced complete or partial lockdown to contain the pandemic, which is subsequently being emulated by other nations. ${ }^{3}$ In the process of flattening the curve of pandemic, the countries have undertaken various diverse and innovative public health approaches. Steps like restriction of travel; intensive screening and testing; field surveillance strategies including contact tracing; isolation and quarantine; and issuing guidelines for school, workplaces, and institutions were being undertaken with partial success. ${ }^{4}$

Various international organizations like the $\mathrm{WHO}^{5}$ the Center for Disease Control and Prevention (CDC), ${ }^{6}$ and the London School of Hygiene and Tropical Medicine ${ }^{7}$ are conducting trainings on COVID-19 covering broad topics like standard precautions, clinical care and infection control, personal protective equipment (PPE), nonpharmacological interventions, emergency preparedness, response, and operational planning. The Ministry of Health and Family Welfare, Government of India, has also developed a variety of training resource materials, webinars, and guidelines related to COVID-19 for sensitizing implementers and educators. ${ }^{8}$ An Integrated Govt. Online Training (iGOT) portal is also being launched with an aim to build the capacity of around 1.50 crore

\begin{abstract}
1,2 Department of Community Medicine, School of Public Health, Postgraduate Institute of Medical Education and Research, Chandigarh, India

Corresponding Author: Sonu Goel, Department of Community Medicine, School of Public Health, Postgraduate Institute of Medical Education and Research, Chandigarh, India, Phone: +91 9914208027, e-mail: sonugoel007@yahoo.co.in

How to cite this article: Upadhyay K, Goel S. Short-term Impact of a Web-based COVID-19 Certificate Program on Knowledge of Global Public Health Professionals. J Postgrad Med Edu Res 2020;54(3): 150-157.

Source of support: International Public Health Management Development Program under Indian Technical and Economic Cooperation, Ministry of External Affairs, Government of India

Conflict of interest: None
\end{abstract}

frontline workers. ${ }^{9}$ None of these courses are providing a single platform where different levels of healthcare workforce from various countries are being trained on best practices of the country.

In response to a virtual meeting (March 15, 2020) by hon. prime minister of India Mr. Narendra Modi with leaders of the South Asian Association for Regional Cooperation (SAARC) regarding coordinated efforts of the region toward the deadly outbreak, the Indian Technical and Economic Cooperation (ITEC), Ministry of External Affairs, Government of India, initiated a program on COVID-19 for building capacity of health workforce of 161 ITEC countries in tackling coronavirus pandemic in these respective countries. Further, the program aims at sharing best 
practices and experiences of India in tackling COVID-19 pandemic for adoption and adaption in their settings. ${ }^{10}$

To support the mission, ITEC approached the Postgraduate Institute of Medical Education and Research (PGIMER), an autonomous government institute of national excellence in India, for building capacity of mid- and senior-level healthcare professionals to manage COVID-19 pandemic in their respective countries through demonstration of best and replicable practices and experiences of India using a short interactive e-learning modular program. The current program, namely "Managing COVID 19 Pandemic: Experience and Best practices of India," was conceived under the existing ITEC-supported flagship "International Public Health Management Development Program" (IPHMDP) with an objective to understand the concepts of COVID-19 and its management, building capacity of health workforce, illustrating best practices and experience, and developing effective decision making by appreciating gaps in current scenario and envision future trends.

\section{Materials and Methods}

\section{Study Settings}

The International Public Health Management Development Program (IPHMDP) was conceived in the year 2016 in Department of Community Medicine and School of Public Health, PGIMER, Chandigarh. It aims to enhance the skills and competencies of middle- and senior-level program managers and academicians for addressing public health challenges and strengthening efficiency of organizations in limited resource settings. The program is in consonance with ITEC, Ministry of External Affairs mission, for establishing relations of mutual concern and interdependence based not only on commonly held ideals and aspirations but also on solid economic foundations. The program is entirely on no-profit basis and first of its kind in the country, which is being conducted in government set-up to enhance management competencies of program managers for improving the performance and productivity of their organizations. Till date, seven programs are been conducted where 212 professionals from 58 countries have been trained in public health management skills.

\section{Study Design and Duration}

A cross-sectional design involving three cohorts of healthcare professionals from various ITEC nations were trained on management of COVID-19 and best practices of India in three batches (April 27-May 1; May 11-15, 2020; and May 18, 2020).

\section{Selection of Participants and Faculty}

The selection of participants was done 1 month prior to the program through open call for registration utilizing the official ITEC website. ${ }^{10}$ The participation was open to medical students, academicians, researchers, healthcare managers, implementers, and policy makers across the globe. The selection of participants was done through a competitive process by taking into account the country, gender, academic profile, organization, and work experience.

The faculty of program involved senior faculty from premier medical institution, health care, implementers, senior program managers, and policy makers, along with administration officers from health and allied departments who are actively involved in COVID-19 management in the country.

\section{Program Contents and Methods}

It is an educational program focused on imparting basic knowledge about COVID-19 pandemic and its management. The course program was developed in accordance with national guidelines on prevention and management of COVID-19.11,12 The topics covered during the training included 28 lectures under eight modules (Fig. 1) demonstrating good practices of India ranging from hospital management to field-based surveillance and administrative aspects. It also contains lectures from motivational speakers and few indigenous yoga practices.

The first module, namely "Understanding COVID," included topics like evolution of the virus, current situation-where are we?, modes of spread of infection, symptoms, and clinical outcomes. The second module was on "infection prevention and environmental disinfection," which highlighted the standard infection control measures and rational use of PPE and biomedical waste management. The third module was diagnosis and clinical management of COVID-19 patients and contacts. In this module, the topics on diagnostic and laboratory procedures, clinical management, along with role of nurses and information technology in COVID-19 were explained. Module 4 was designed focusing on field and public health measures, which included topics like social distancing, screening and triage, contact tracing, isolation, quarantine, and other personal safety measures for frontline field staff. The fifth module elaborated on educational and behavioral approaches like integrated psychological support, managing stigma, and ensuring motivation and morale. The administrative and management issues were discussed in the sixth module where lectures on best practices adopted by the Municipal Corporation department and police were showcased along with good practices in tertiary care hospitals like quarantine center management and reorganization of healthcare services were deliberated with participants. The last module was on emerging issues, which covered topics focusing on ethical issues on COVID19 , role of nutrition, combating mental stress through yoga, and media advocacy. Three panel discussions were also conducted with technical experts of the institute $(n=2)$ and senior decision makers at the national/state level $(n=1)$, respectively. The USP of the program was the short-duration sessions (each lasting 15-20 minutes), its easy accessibility, and single platform covering major topics of common interest, practicality, and easily replicable in different settings. The program had no registration fees. It was broadcasted online on the YouTube channel requiring with minimum logistics.

\section{Data Collection Instruments}

A pre- and posttest questionnaire (having with 27 multiple-choice questions on different topics, viz., hospital management to fieldbased surveillance and administrative aspects) was prepared after extensive review of the literature and guidelines developed by eminent agencies. Further feedback questionnaire was designed, which included parameters regarding instructions about the program, takeaway from the course, resource material, program content, and relevancy of the course to job responsibilities of the participants (Fig. 2).

\section{Data Management and Analysis}

Data were collected through Google Forms, exported to MS Excel, and data cleaning was done. For each pre- and post-question, a correct response was scored "one" and an incorrect response was scored "zero." The overall feedback of program was assessed for 10 parameters using the five-point Likert scale $(1=$ poor, $2=$ average, $3=$ good, $4=$ very good, $5=$ excellent). The analysis was done using the Statistical Package for Social Sciences (SPSS) 


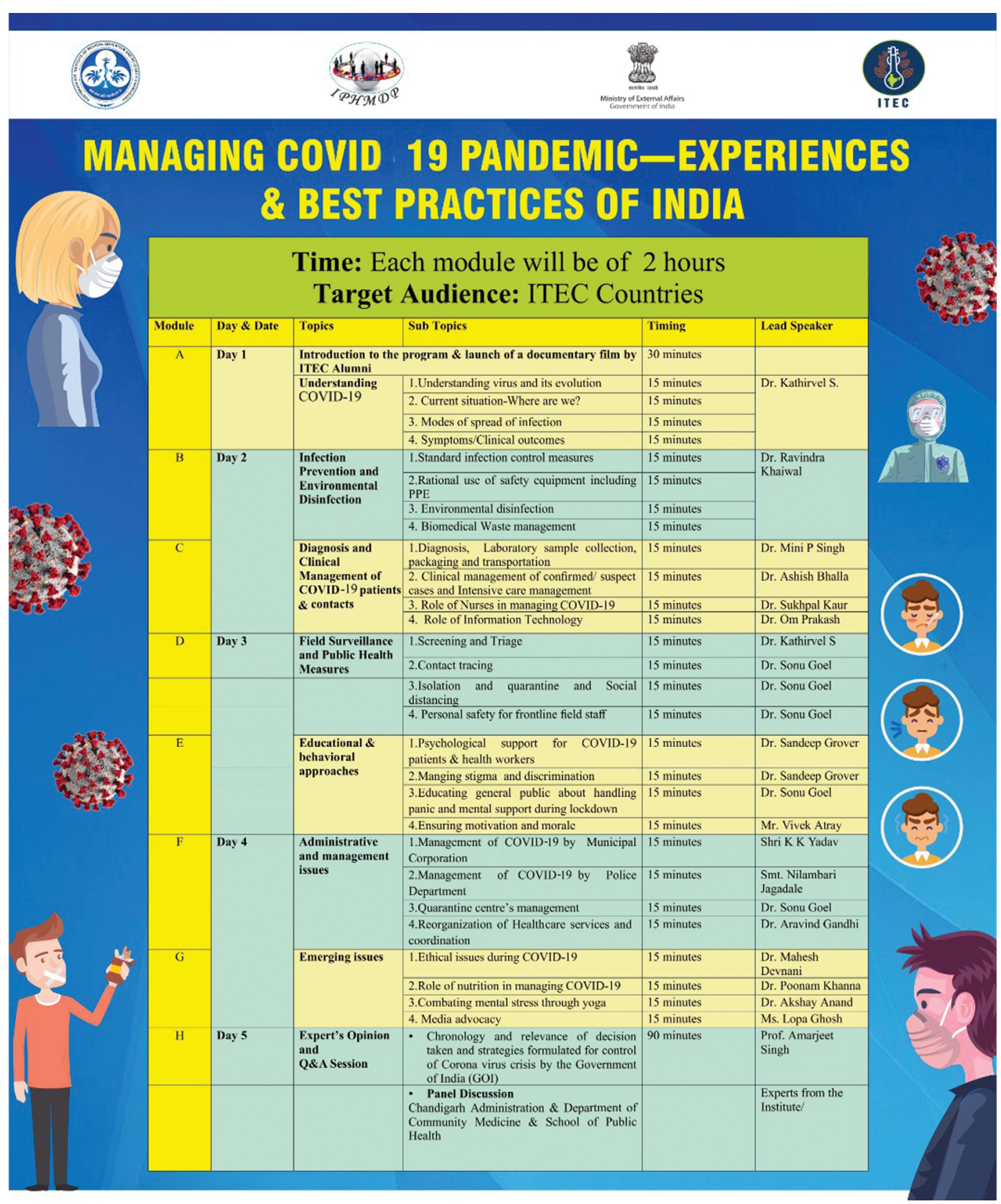

Fig. 1: Schedule of the Web-based COVID-19 certificate program for Indian Technical and Economic Cooperation participants

version 20. The demographic characteristics of participants were reported as percentage, mean, standard deviations, whereas paired $t$-tests were used to compare differences in participant's knowledge scores before and after the program. The social media responses were assessed based upon the number of expressions and engagements on social media engines (Twitter, Facebook, and YouTube). "Impressions" are the total number of times any user could have potentially seen the post on social media, whereas the "engagement" refers to mentions, retweets, comments, and new followers for the program.

\section{Ethics}

The permission for the program was obtained from the head of the institute. There are no direct identifiers in the study.

\section{Results}

A total of 131 participants from 17 countries of 5 continents attended the program (Fig. 3). Out of total, 89 (67.9\%) were males and $42(32.1 \%)$ were females. The number of graduates $(n=68$, $51.9 \%$ ) and postgraduates ( $n=63,48.1 \%)$ were almost equal. Majority of participants were clinicians $(n=55,42 \%)$ followed by other healthcare staff, viz., lab technicians, pharmacists, information technology managers ( $n=42,32.1 \%)$, academicians ( $n=19,1.5 \%)$, and public health professionals ( $n=15,11.5 \%$ ) (Table 1).

The impact of the program on participant's knowledge was assessed over seven modules covering 28 lectures. Participants who attempted both the pre- and post-assessment test were included in the study $(n=90)$. It was seen that the participants have shown 


\section{Department of Community Medicine \& School of Public Health, PGIMER, Chandigarh}

This feedback is to assess whether the learning objectives of the module were achieved. Kindly reflect carefully. Tick mark on the scale of 1 (poor) to 5 (excellent)

Overall Feedback Form

\begin{tabular}{|c|c|c|c|}
\hline S.No. & Particulars & 1 & 2 \\
\hline 1 & $\begin{array}{l}\text { I am being regularly informed about the } \\
\text { instructions before and during the program }\end{array}$ & & \\
\hline 2 & $\begin{array}{l}\text { I had the prior knowledge of what would be my } \\
\text { "take-away" from the course }\end{array}$ & & \\
\hline 3 & Presentations were well prepared and on target & & \\
\hline 4 & $\begin{array}{l}\text { The best practices shared in this course was } \\
\text { effective in managing COVID-19 in my country }\end{array}$ & & \\
\hline 5 & $\begin{array}{l}\text { The program overcame language and other } \\
\text { barriers and facilitated understanding }\end{array}$ & & \\
\hline 6 & $\begin{array}{l}\text { The pace and the sequencing of the sessions by } \\
\text { facialitators facilitators easy transfer of learning inputs }\end{array}$ & & \\
\hline 7 & $\begin{array}{l}\text { The webinar program engaged me in active learning related } \\
\text { to its goal }\end{array}$ & & \\
\hline 8 & The course met its stated objectives & & \\
\hline 9 & This course was relevant to my job responsibilities & & \\
\hline 10 & I intend to use what I learned from the course in my work & & \\
\hline
\end{tabular}

19. What are the three things you really like about this program?

1.

2.

3.

20. Any suggestions you would like to offer for future programs

Thank you very much for the thoughtful feedback and participating in the program

Fig. 2: Feedback questionnaire for the program

significant improvement in overall knowledge in all the modules (Table 2).

Figure 4 depicts feedback of participants given on various aspects of the program. Majority (93.1\%) of participants felt the program was excellent or very good. The participants excellent response ranged from 42 to $74 \%$ with maximum scores were on relevancy of the program (74.4\%) and its application in the workplace (74.4\%). This was followed providing primary information regarding the program (73.4\%), adequacy of teaching material (73.4\%), overcame language and other barriers (68\%), course met its stated objectives (68\%), engagement in active learning related to its goal (65.9\%), the pace and the sequencing of the sessions (59.5\%), and effectiveness of best practices in my country (54.2\%) (Fig. 4).
Box 1 shows the most liked elements of the course, which were gathered through the YouTube comments posted during the program.

Figure 5 represents the social media outreach garnered by the different posts shared during the online program. It is apparent that the social media outreach has gradually increased in the time span, which was being reported. After analyzing the data for 5 continuous days, it has been recorded that the maximum number of engagements on Twitter and Facebook were 1,330 and 708 , respectively. On the other hand, maximum number of impressions recorded on both Twitter and Facebook were 13,521 and 8,800 , respectively. There was a gradual increase in the number of followers on the social media pages including Twitter, Facebook, and YouTube (Fig. 5). 


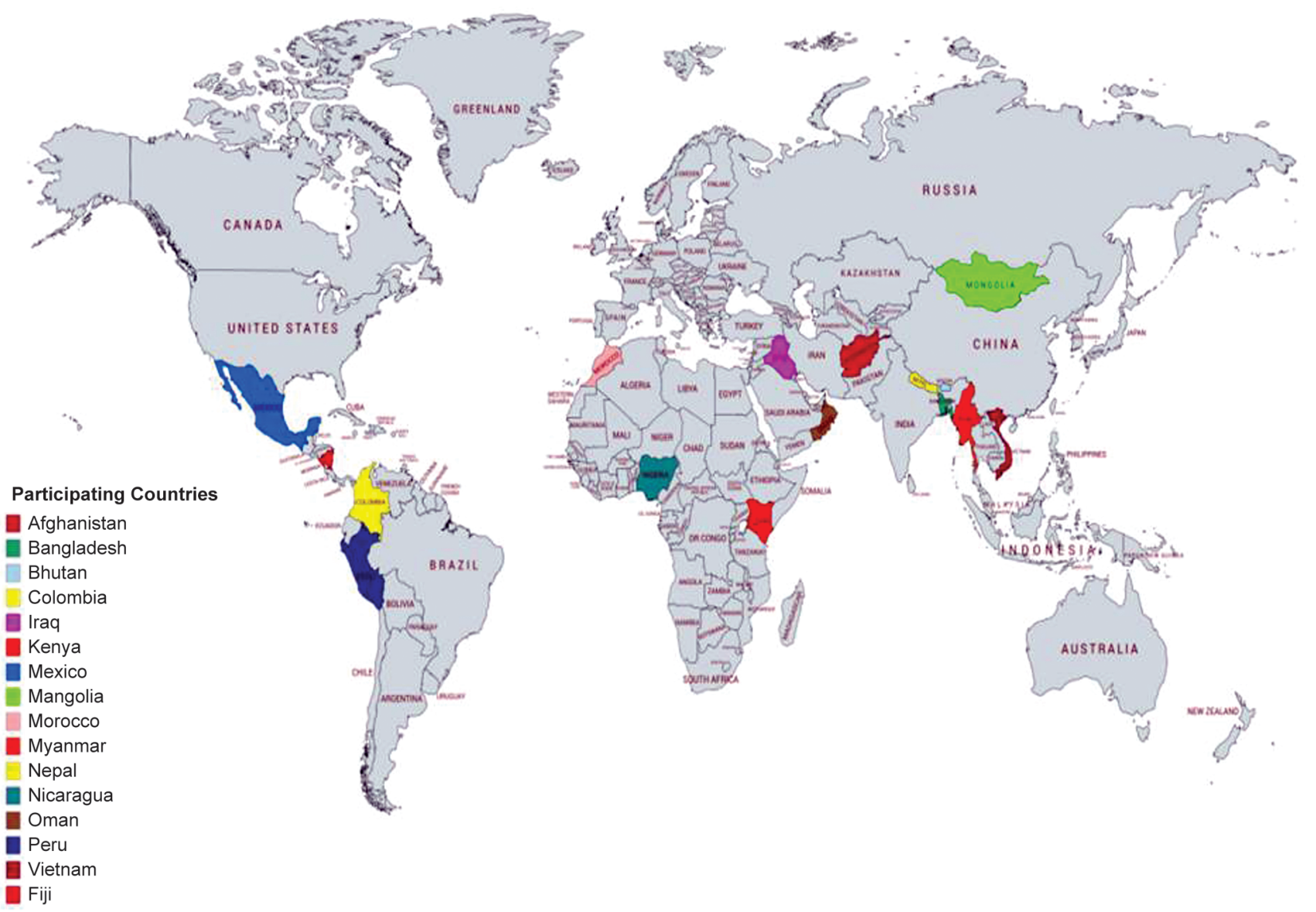

Fig. 3: Geographical distribution of participants-Country-wise

Table 1: Distribution of participants

\begin{tabular}{|c|c|c|c|}
\hline \multicolumn{2}{|c|}{ Demographic characteristics } & \multirow{2}{*}{$\frac{\text { Number }}{89}$} & \multirow{2}{*}{$\frac{\text { Percentage }}{67.9}$} \\
\hline Gender & Male & & \\
\hline & Female & 42 & 32.1 \\
\hline \multirow[t]{4}{*}{ Age (in years) } & $20-35$ & 66 & 50.4 \\
\hline & $36-50$ & 50 & 38.2 \\
\hline & $50-65$ & 11 & 8.4 \\
\hline & Above 65 & 4 & 3.1 \\
\hline \multirow[t]{2}{*}{ Qualification } & Postgraduate & 63 & 48.1 \\
\hline & Graduate & 68 & 51.9 \\
\hline \multirow[t]{4}{*}{ Profession } & Clinicians & 55 & 42.0 \\
\hline & Academicians & 19 & 14.5 \\
\hline & Public health professionals & 15 & 11.5 \\
\hline & Other healthcare staff & 42 & 32.1 \\
\hline \multirow[t]{5}{*}{ Continents } & Asia & 88 & 67.17 \\
\hline & Africa & 28 & 21.37 \\
\hline & North America & 7 & 5.34 \\
\hline & South America & 7 & 5.34 \\
\hline & Australia/Oceania & 1 & 0.76 \\
\hline
\end{tabular}

\section{Discussion}

The program was the maiden effort from a tertiary care institute of national eminence of India to increase the capacity of policy makers, implementers, and academia of various countries across the globe regarding COVID-19 with minimal resource and time constraints. As a result of successful completion of the program, the participants were able to gain adequate knowledge and skills in managing the greatest pandemic of the country in their respective countries. The online platform adopted for the program not only allowed large number of participants across continents to participate in it but also minimized cost and other resources, enabled engagement of faculty from diverse background and location, along with access to relevant and good-quality training material to the participants at their workplaces, thus paving a way to support academic continuity during the pandemic. Such online programs have been successfully conducted across various other settings with varied degree of success. Jessica et al. used online webinar to train 1,555 participants from 116 countries, which showed an increase in their knowledge and skills on various dimension similar to the current program. ${ }^{13}$ Stephen had demonstrated that online webinars can be successfully conducted to train participants when on-site courses are cancelled..$^{14}$ Another study by Cleland et al. on health professional educators also used the virtual mode through webinar and trained participants from various continents, which is similar to the current study. ${ }^{15}$

The study not only measured feedback of respondents through anonymous poll but also through social media responses of the participants. Similar to the current study, various studies have measured feedback of participants through social media 
Impact of a Web-based COVID-19 Certificate Program

Table 2: Impact of program on participant's knowledge score regarding various dimensions of COVID-19

\begin{tabular}{|c|c|c|c|c|c|}
\hline Module $(n=90)$ & Pretest (mean $\pm S D)$ & Posttest (mean $\pm S D)$ & $t$ & $d f$ & Sig. (two-tailed) \\
\hline Module1: Understanding COVID-19 & $1.26 \pm 1.04$ & $3.01 \pm 0.86$ & -12.3 & 89 & 0.000 \\
\hline $\begin{array}{l}\text { Module 2: Infection prevention and environmental } \\
\text { disinfection }\end{array}$ & $1.36 \pm 0.72$ & $2.96 \pm 0.85$ & -14.4 & 89 & 0.000 \\
\hline $\begin{array}{l}\text { Module 3: Diagnosis and clinical management of } \\
\text { COVID-19 patients and contact }\end{array}$ & $1.64 \pm 0.89$ & $3.30 \pm 0.86$ & -13.0 & 89 & 0.000 \\
\hline Module 4: Field surveillance and public health measures & $1.10 \pm 0.73$ & $2.20 \pm 1.00$ & -8.3 & 89 & 0.000 \\
\hline Module 5: Educational and behavioral approaches & $1.42 \pm 0.85$ & $2.73 \pm 0.61$ & -12.1 & 89 & 0.000 \\
\hline Module 6: Administrative and management issues & $1.79 \pm 0.75$ & $3.12 \pm 0.85$ & -10.8 & 89 & 0.000 \\
\hline Module 7: Emerging issues & $0.75 \pm 0.42$ & $1.73 \pm 0.87$ & -10.1 & 89 & 0.000 \\
\hline Overall score & $13.67 \pm 2.83$ & $19.22 \pm 3.14$ & -36.1 & 89 & 0.000 \\
\hline
\end{tabular}

$n$ denotes the number of participants

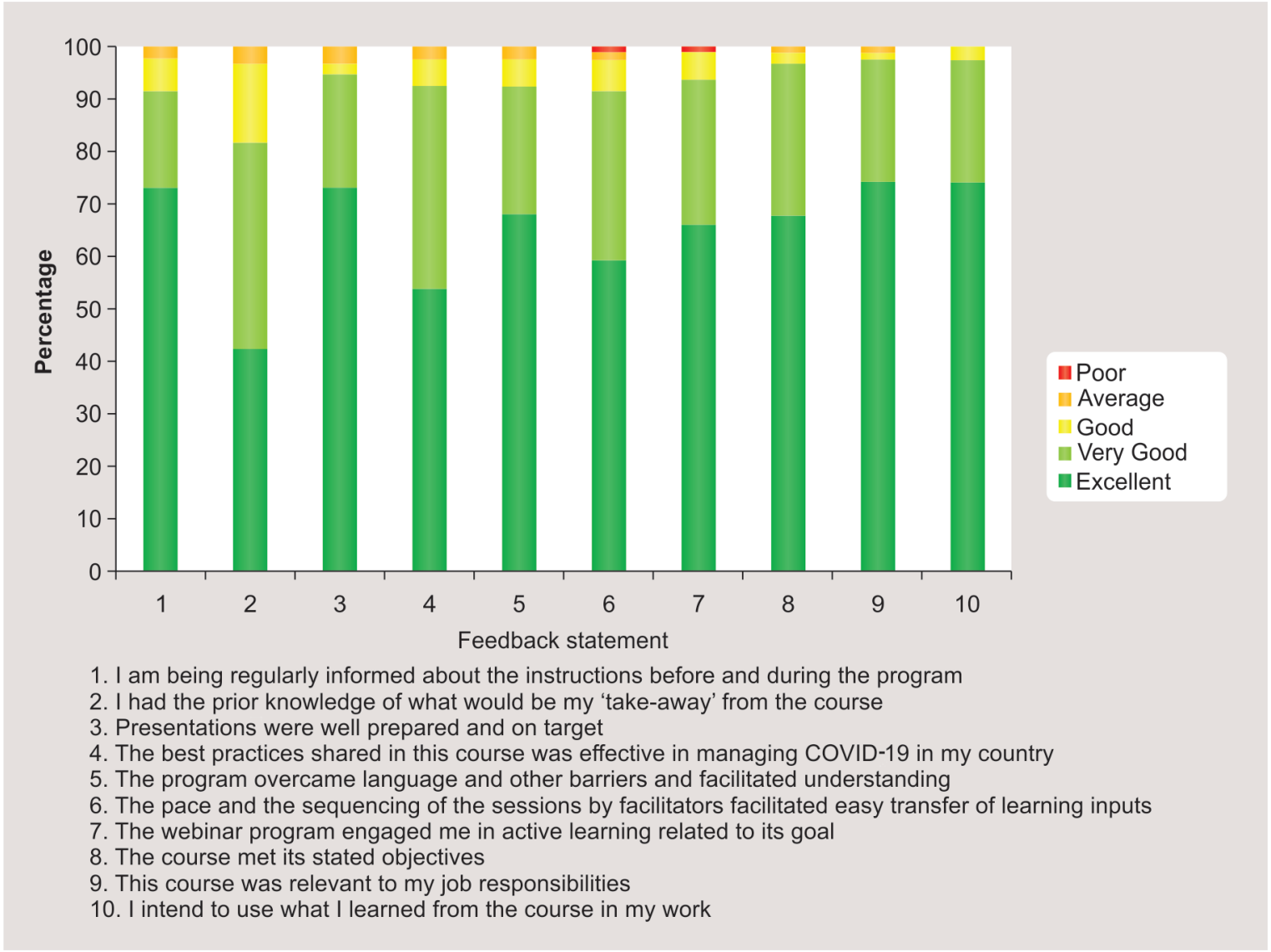

Fig. 4: Feedback of participants regarding the certificate program on COVID-19

responses on Twitter, Facebook, YouTube, etc. Through these platforms, the participants were free to express their feelings. It not only helped them interact with the organizers and facilitators but also expressing their likes and dislikes, making suggestions for possible improvements, and even recommendations were suggested. ${ }^{14,16}$

There were several strengths of the study. First, the experiences and inputs received from facilitators of various backgrounds were used to design the comprehensive nature of the program. Second, the online mode helped in capacity building of health professionals of different professional background who cannot afford to come and attend a formal training program. Third, the participants not only gained best practices of India but also learnt good initiatives of other countries through peer-to-peer learning. Fourth, the online mode of learning was convenient to all stakeholders and utilized minimal resources, which was helpful in boosting the academic continuity during the pandemics.

The present study had few limitations. The study did not have a control group, thus the increase in the knowledge and skills due to the program may not be conclusively stated. Second, the faceto-face interaction of participant with facilitators was missing; thus, many queries were not addressed during the program. Third, there were few technical glitches encountered during the program due to online modality. 
Box 1: A few qualitative feedbacks of the participants about the program

\begin{tabular}{cl}
\hline 1. & Practical experience sharing \\
2. & Excellent coordination of team members \\
3. & Experts' panel discussion was highlight of the program \\
4. & Highly interactive and engaging despite the online mode \\
5. & Best case practices were very useful \\
6. & Excellent delivery of lectures, resourceful presentations, and updated and valuable information \\
7. & Well-planned and organized sessions \\
8. & All the pioneers of India at one platform \\
9. & Sessions on motivation and yoga demonstration were very interesting \\
10. & Overall, like the content, mode of delivery, and facilitators of the program \\
\hline
\end{tabular}

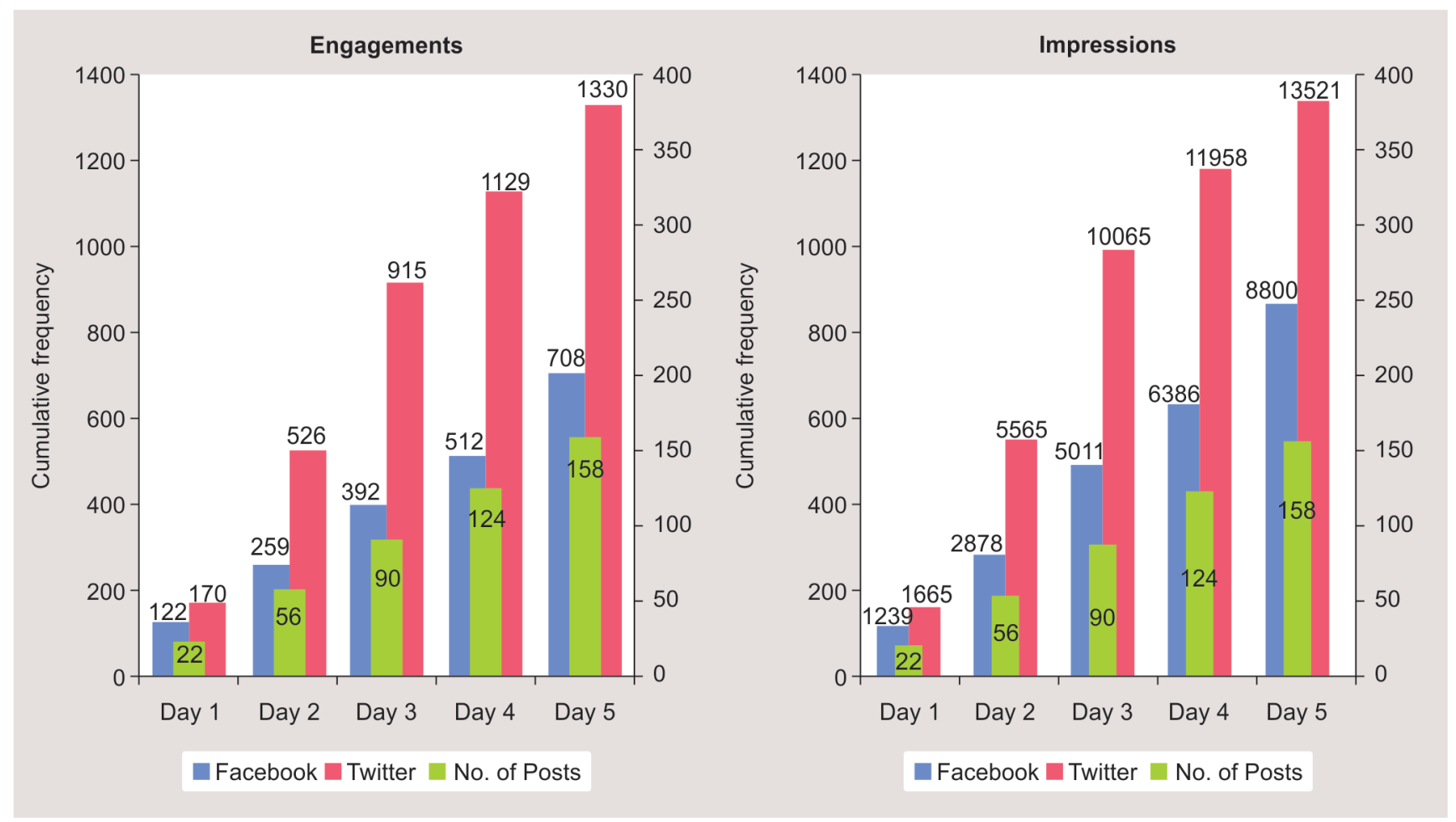

Fig. 5: Social media outcomes of COVID-19 certificate program

\section{Conclusion}

The current program was the first of its kind, which was supported by the Ministry of External Affairs, Government of India, under ITEC scheme for 161 ITEC countries. This program was designed with a need to disseminate knowledge for effective planning, implementing and monitoring public health crises faced due to coronavirus, and overall improve effectiveness and efficiency of the healthcare delivery system. The program has not only successfully shown its effectiveness in increasing the knowledge and skills of participants in managing corona pandemic but also helped in enhancing image of the country by showcasing best practices of India to global participants.

\section{Acknowledgments}

We acknowledge the support of ITEC, Ministry of External Affairs, Government of India, and all participants of ITEC nations for their active participation in the consensus.

\section{References}

1. Public Health \& Management Colleges in India - Fees, Courses, Placements, Cut Off, Admission [Internet]. [cited 2020 Jun 8]. Available from: https://www.shiksha.com/medicine-health-sciences/publichealth-management/colleges/colleges-india?uaf[]=substream\&ua $\mathrm{f}[]=$ city\&uaf[]=state\& $\mathrm{rf}=$ filters.

2. Coronavirus disease (COVID-19) [Internet]. [cited 2020 Jun 19]. Available from: https://www.youtube.com/watch?v=OFGiy6t7k5E.

3. Lockdown: Which countries are in lockdown? How many people? | World | News | Express.co.uk [Internet]. [cited 2020 Jun 28]. Available from: https://www.express.co.uk/news/world/1260709/lockdownwhich-countries-are-in-lockdown-how-many-people-coronaviruscases.

4. Technical guidance [Internet]. [cited 2020 Jun 19]. Available from: https://www.who.int/emergencies/diseases/novel-coronavirus-2019/ technical-guidance.

5. Online training [Internet]. [cited 2020 Jun 19]. Available from: https:// www.who.int/emergencies/diseases/novel-coronavirus-2019/ training/online-training. 
6. Training for Healthcare Professionals |CDC [Internet]. [cited 2020 Jun 19]. Available from https://www.cdc.gov/coronavirus/2019-ncov/hcp/ training.html.

7. COVID-19 Coronavirus - Online Course-FutureLearn [Internet]. [cited 2020 Jun 21]. Available from: https://www.futurelearn.com/courses/ covid19-novel-coronavirus.

8. Training Resources for Covid 19 Management [Internet]. [cited 2020 Jun 19]. Available from: https://www.mohfw.gov.in/pdf/ NotificationoflCMgui.

9. IGOT [Internet]. [cited 2020 Jun 20]. Available from: https://igot.gov. in/igot/.

10. ITEC:Indian Technical and Economic Cooperation [Internet]. [cited 2020 Jun 20]. Available from: https://www.itecgoi.in/ upcomingcourse.php.

11. COVID19 Guidelines:: National Centre for Disease Control (NCDC) [Internet]. [cited 2020 Jun 28]. Available from: https://ncdc.gov.in/ index1.php?lang $=1 \&$ level $=1 \&$ sublinkid $=703 \&$ lid $=550$.

12. Technical guidance [Internet]. [cited 2020 Jun 28]. Available from: https://www.who.int/emergencies/diseases/novel-coronavirus-2019/ technical-guidance.

13. Ali SR, Dobbs TD, Whitaker IS. Webinars in plastic and reconstructive surgery training - a review of the current landscape during the
COVID-19 pandemic [internet]. J Plast, Reconstruct Aesthet Surg Church Livingst 2020;73(7):1357-1404. DOI: 10.1016/j. bjps.2020.05.038Available from: https://www.ncbi.nlm.nih.gov/pmc/ articles/PMC7243775/.

14. Mackinnon J, Bremshey A. Perspectives from a webinar: COVID19 and sexual and reproductive health and rights. Sex Reprod Heal matters [Internet] 2020;28(1):1763578. Available from: https://www.tandfonline.com/doi/abs/10.1080/26410397.2020. 1763578.

15. Cleland J, McKimm J, Fuller R, et al. Adapting to the impact of COVID-19: sharing stories, sharing practice. Med Teach [Internet] 2020;42(7):772-775. DOI: 10.1080/0142159X.2020.1757635.

16. Singhal TK. Impact of Social Media Expressions on Engagement and Trust of Customers Assessment of Impact of loT Origin Data on Effectiveness of Supply Chain Management: A Research Study with Specific Reference to Automotive Industry in India View project Currently working on Business Model Innovation metrics that could be applied to Managed Services Providers, particularly Smart City Solutions View project Impact of Social Media Expressions on Engagement and Trust of Customers INTRODUCTION [Internet]. [cited $2020 \mathrm{Jul}$ 4]. Available from: https://www.researchgate.net/ publication/309559028. 